\title{
Survey of Awareness of Thyroid Disorders among the Riyadh Population, Central Region of Saudi Arabia Atheer Mohammed D Alotaibi ${ }^{1}$, Abdulrahman Ibrahim S Almousa ${ }^{2}$ \\ ${ }^{1}$ Almaarefa Colleges for science and Technology, College of Medicine, Riyadh, ${ }^{2}$ Prince Sattam bin Abdulaziz University, Akharj, Saudi Arabia
}

\begin{abstract}
Background: Thyroid diseases are among the commonest endocrine disorders worldwide and attention to physical examination findings, combined with selected laboratory and radiologic tools and aids in the early diagnosis and treatment of thyroid endocrine disorders is fundamental. Health education is considered an essential component to improve knowledge and change behavior. People affected by thyroid diseases often have inadequate knowledge about the nature of thyroid diseases, its risk factors and associated complication. Objectives: The aim of this study was to assess the awareness of the Riyadh population with various aspects of thyroid diseases. Methods: A cross-sectional study was carried out during the period from 1 December 2017 to 28 February 2018 in Riyadh city. A random, representative sample from Saudi nationals were included. Those who are under 18 years old were excluded. Systematic random sampling technique was followed. An online well constructed questionnaire translated into Arabic was disseminated and self administered by each participant. Data were analyzed by SPSS version 16, using descriptive statistics. Results: The total number of participants was 870 among which 297 (34.1\%) were males and 573 (65.9\%) were females. The participants were classified into 4 age groups, most of them were in the 31-50 years old group, counting 492 (56.5\%). Only $6.6 \%$ among the participants did not know what the thyroid gland is, while $93.4 \%$ have chosen specific answers that are facts regarding the thyroid on different levels of knowledge. Among participants, $17 \%$ related thyroid disorders to disturbances in the menstrual cycle, recurrent miscarriage, and birth of dead fetuses, while $30.3 \%$ related that to psychological factors as depression, confusion, lack of concentration, mood swings, and anxiety, $27.4 \%$ to neck and joint pain with fatigue and weight loss, and $25.3 \%$ constipation and/or diarrhea, voice changes and swelling of the neck. Among our participants, $16.8 \%$ reported suffering from hypothyroidism. Regarding hypothyroidism, 30.9\% answered yes to the question regarding whether or not ionized salt has a role in the treatment of hypothyroidism, when $22.2 \%$ responded with 'No' and the majority $(46.9 \%)$ responded 'I do not know'. The majority (39.0\%) answered 'Yes' to whether the treatment can be stopped when investigations become normal in hypothyroidism, and (43.6\%) answered 'I do not know,' in hyperthyroidism. Moreover, $26.6 \%$ thought that herbal remedy can cure hypothyroidism as well as (26.0\%) in hyperthyroidism. Conclusion: This study recommended that health policy makers must conduct more effective health education sessions to increase knowledge of the population and their caregivers about various aspects of thyroid diseases and the importance of compliance with its treatment.
\end{abstract}

Keywords: Awareness, thyroid diseases, Knowledge, Riyadh City, Saudi Arabia

\section{INTRODUCTION}

Thyroid gland is an endocrine organ located in the anterior aspect of the neck in front of the trachea. The function of this gland is to produce sufficient amount of thyroid hormones which will primarily influence the metabolic rate and protein synthesis. Thyroid hormones also have other effects such as development of tissues and organs. The production of thyroid hormone is regulated by hypothalamic pituitary axis through thyroid stimulating hormone from anterior pituitary gland and thyroid releasing hormone from the hypothalamus.

Prevalence of thyroid disorders is a very common medical condition. Symptoms of thyroid disorders depending on the condition of thyroid gland functions ${ }^{[1]}$. The function of the thyroid can be primarily affected from the gland itself (most common) or secondarily affected from higher centers signal in the brain (hypothalamic pituitary axis). This effect on the gland function will result in one of two types of disorders hypothyroidism or hyperthyroidism. Hypothyroidism is the most prevalent type affecting $4-5 \%$ in the developed countries. While it's is more common in areas with iodine deficiency ${ }^{[2]}$.

The pattern of the disorders distribution depends on age, ethnicity and geographic factors especially in iodine deficient areas. Despite being one the most prevalent medical condition, thyroid disorders are the most underdiagnosed and neglected chronic health conditions globally ${ }^{[3,4]}$.

During clinical assessment of thyroid disorders patient may present with variety of manifestations involving major systems of the body like endocrine, cardiovascular, central nervous system, musculoskeletal, hematological, reproductive, gastrointestinal and dermatological [5]. These manifestations can be confused with other medical conditions because; they are not specific to thyroid disorders only. 
Thyroid function test panel is commonly used for screening and evaluating thyroid disorders. The American Thyroid Association recommends that adults must be screened for thyroid disorders by measurement of the serum thyrotropin concentration at the age 35 years and every 5 years thereafter ${ }^{[6]}$.

Physiological thyroid gland function is critical for neurocognitive development, growth and development throughout childhood and adolescence, and maintenance of normal physiological functions in adults ${ }^{[7]}$.

Hypothyroidism is case of deficient production of thyroid hormone by the thyroid gland. It is of two types; primary (abnormality in thyroid gland itself) or secondary/central (hypothalamic or pituitary disease) ${ }^{[8]}$.

Among hypothyroidism cases, primary hypothyroidism is the etiology is about $99 \%$ of the cases. The term subclinical hypothyroidism is used to define that grade of primary hypothyroidism, in which there is an elevated thyroid-stimulating hormone (TSH) concentration in the presence of normal serum free thyroxin (T4) and triiodothyronine concentrations ${ }^{[9]}$. Hyperthyroidism is the case of excessive production of thyroid hormone by the thyroid gland. Thyrotoxicosis is the case of excessive thyroid hormone levels due to any cause and thus, it includes hyperthyroidism ${ }^{[10]}$.

\section{STUDY OBJECTIVE}

Evaluating the knowledge of the Riyadh population about thyroid gland and its disorders, their causes, diagnostic methods available, prevention strategies and treatment options available. Detecting the awareness of the population about the possible complications and the impact of the disorders on their life.

\section{Material and Methods}

A cross-sectional study was carried out during the period from 1 December 2017 to 28 February 2018 in Riyadh city. A random, representative sample from Saudi nationals were included. Those who are under 18 years old were excluded. The sample size was calculated using the sample size equation: $n=z^{2} p(1-p) / e^{2}$, considering target population more than 1000 , and study power 95\%. Systematic random sampling technique was followed. An online well constructed questionnaire translated into Arabic was disseminated and self administered by each participant. It covers the following items: age, sex, knowledge of what thyroid gland and what is its diseases, causes, complications, management and prevention measures of kidney diseases, whether the participant has/had thyroid disease, duration of illness, diagnosis, concurrent morbidities and type of treatment.

A total of 870 samples were collected; the primary focus of Symptoms of thyroid troubles knowledge about Hypothyroidism and hyperthyroidism. Filled questionnaires were reviewed for completeness and accuracy before data entry, then the data were coded and analyzed by SPSS version 16 (SPSS Inc., Chicago, Illinois, USA) using Chisquare test. Participants were informed that participation was completely voluntary, a written consent was obtained from each participant before research, no name was recorded on the questionnaires and all of the personal information of participants was kept confidential.

\section{RESULTS}

The total number of participants was 870 among which 297 (34.1\%) were males and 573 $(65.9 \%)$ were females. The participants were classified into 4 age groups, most of them were in the $31-50$ years old group, counting 492 (56.5\%). Only $6.6 \%$ among the participants did not know what the thyroid gland is, while $93.4 \%$ have chosen specific answers that are facts regarding the thyroid on different levels of knowledge. Among participants, $17 \%$ related thyroid disorders to disturbances in the menstrual cycle, recurrent miscarriage, and birth of dead fetuses, while $30.3 \%$ related that to psychological factors as depression, confusion, lack of concentration, mood swings, and anxiety, $27.4 \%$ to neck and joint pain with fatigue and weight loss, and $25.3 \%$ constipation and/or diarrhea, voice changes and swelling of the neck. Among our participants, $16.8 \%$ reported suffering from hypothyroidism. Regarding hypothyroidism, $30.9 \%$ answered yes to the question regarding whether or not ionized salt has a role in the treatment of hypothyroidism, when $22.2 \%$ responded with 'No' and the majority (46.9\%) responded 'I do not know'. The majority (39.0\%) answered 'Yes' to whether the treatment can be stopped when investigations become normal in hypothyroidism, and (43.6\%) answered 'I do not know,' in hyperthyroidism. Moreover, $26.6 \%$ thought that herbal remedy can cure hypothyroidismas well as $(26.0 \%)$ in hyperthyroidism. Additionally, $74.6 \%$ think that cabbage, cauliflower and soy products should be avoided in case of hypothyroidism.

Table (1): Sex, age and knowledge about thyroid gland and thyroid troubles among Riyadh population, (2017- 2018). 


\begin{tabular}{|c|c|c|}
\hline & Frequency & Percent \\
\hline $\begin{array}{l}\text { Sex } \\
\quad \text { Female } \\
\text { Male }\end{array}$ & $\begin{array}{l}573 \\
297\end{array}$ & $\begin{array}{l}65.9 \\
34.1 \\
\end{array}$ \\
\hline $\begin{array}{c}\text { Age group } \\
18-30 \\
31-50 \\
>50 \\
\end{array}$ & $\begin{array}{l}279 \\
492 \\
100 \\
\end{array}$ & $\begin{array}{l}32.0 \\
56.5 \\
11.5 \\
\end{array}$ \\
\hline $\begin{array}{l}\text { What is the thyroid gland } \\
\text { I don't know } \\
\text { gland lies in the front of the neck } \\
\text { Important gland for metabolism and all body functions } \\
\text { Important endocrine gland } \\
\text { Important endocrine gland lies in front of the trachea }\end{array}$ & $\begin{array}{l}57 \\
323 \\
221 \\
85 \\
150\end{array}$ & $\begin{array}{c}6.6 \\
37.1 \\
24.4 \\
9.8 \\
17.2\end{array}$ \\
\hline $\begin{array}{l}\text { Function of the thyroid gland } \\
\text { Regulation of body temperature, blood pressure, growth and metabolism } \\
\text { Regulation of growth } \\
\text { Regulation of body temperature } \\
\text { Regulation of body temperature and blood pressure } \\
\text { Regulation of using of body energy } \\
\text { I don't know }\end{array}$ & $\begin{array}{l}237 \\
102 \\
171 \\
139 \\
165 \\
56\end{array}$ & $\begin{array}{l}27.2 \\
11.7 \\
19.6 \\
15.9 \\
19.0 \\
7.2\end{array}$ \\
\hline $\begin{array}{l}\text { Symptoms of thyroid troubles } \\
\text { Neck pain, joint pain, joint weakness, excessive weight loss, fatigue and palpitations } \\
\text { Swelling of the neck, voice changes, constipation and/or diarrhea for long periods } \\
\text { Depression, confusion, lack of concentration, mood swings, anxiety } \\
\text { Disturbance in women's menstrual cycle, recurrent miscarriage, birth of dead fetus }\end{array}$ & $\begin{array}{l}238 \\
220 \\
264 \\
148\end{array}$ & $\begin{array}{l}27.4 \\
25.3 \\
30.3 \\
17.0\end{array}$ \\
\hline
\end{tabular}

Table (2): Knowledge about Hypothyroidism among Riyadh population, (2017_-_2018).

\begin{tabular}{|c|c|c|c|}
\hline \multirow{2}{*}{ Knowledge } & Yes & No & I don't know \\
\hline & No. $(\%)$ & No. $(\%)$ & No. $(\%)$ \\
\hline Is iodized salt have a role in treatment of Hypothyroidism & $269(30.9)$ & $193(22.2)$ & 408(46.9) \\
\hline Herbal remedy can cure thyroid disorders & $231(26.6)$ & 244(28.0) & $395(45.4)$ \\
\hline Can you stop treatment of hypothyroidism when the investigations were normal & $339(39.0)$ & $256(29.4)$ & $275(31.6)$ \\
\hline Can you stop treatment of hypothyroidism in pregnancy because it harms the fetus & $435(50.0)$ & $267(30.7)$ & $168(19.3)$ \\
\hline Can women with thyroid insufficiency conceive normally & $314(36.1)$ & $126(14.5)$ & $430(49.4)$ \\
\hline Are cabbage, cauliflower and soy products should be avoided in case of hypothyroidism & 649(74.6) & $93(10.7)$ & $128(14.7)$ \\
\hline Is Hypothyroidism a genetic disease & $357(41.0)$ & $323(37.1)$ & 19.(218) \\
\hline Is Hypothyroidism infectious disease & $152(17.5)$ & 694(79.8) & $24(2.8)$ \\
\hline Is radioactive iodine one of the therapeutic options & $507(58.3)$ & $90(10.3)$ & 273(31.4) \\
\hline
\end{tabular}

Table (3): Knowledge about hyperthyroidism among Riyadh population(2017- 2018).

\begin{tabular}{|c|c|c|c|}
\hline \multirow[t]{2}{*}{ Knowledge } & Yes & No & $\begin{array}{l}\text { I don't } \\
\text { know }\end{array}$ \\
\hline & No. $(\%)$ & No. $(\%)$ & No. $(\%)$ \\
\hline Herbal remedy can cure thyroid disorders & $226(26.0)$ & $212(24.4)$ & 432(49.7) \\
\hline Can you stop treatment of hyperthyroidism when the investigations were normal & $251(28.9)$ & $240(27.6)$ & $379(43.6)$ \\
\hline Can you stop treatment of hyperthyroidism in pregnancy because it harms the fetus & $172(19.8)$ & $242(27.8)$ & $456(52.4)$ \\
\hline Can women with hyperthyroidism conceive normally & $387(44.5)$ & $107(12.3)$ & $376(43.2)$ \\
\hline $\begin{array}{l}\text { Are cabbage, cauliflower and soy products should be avoided in case of } \\
\text { hyperthyroidism }\end{array}$ & $106(12.2)$ & $104(12.0)$ & $660(75.9)$ \\
\hline Is hyperthyroidism a genetic disease & $168(19.3)$ & $359(41.3)$ & $343(39.4)$ \\
\hline Is hyperthyroidism infectious disease & $31(3.6)$ & $636(73.1)$ & $203(23.3)$ \\
\hline Is radioactive iodine one of the therapeutic options of hyperthyroidism & $273(31.4)$ & $90(10.3$ & $507(58.3)$ \\
\hline Does daily diet affect thyroid function? & $506(58.2)$ & $108(12.4)$ & $256(29.4)$ \\
\hline
\end{tabular}


Table (4): Thyroid troubles, treatment, investigations and family history of thyroid troubles among Riyadh population,(2017-2018) .

\begin{tabular}{|l|c|c|}
\hline & Frequency & Percent \\
\hline Having thyroid troubles & 554 & 63.7 \\
No & 146 & 16.8 \\
Hypothyroidism & 17 & 2.0 \\
Hyperthyroidism & 153 & 17.6 \\
\hline Don't know & & \\
\hline Using of medications for thyroid troubles & 142 & 16.3 \\
Yes & 728 & 83.7 \\
No & 410 & \\
\hline Have you ever done thyroid gland investigations & 460 & 47.1 \\
Yes & & 52.9 \\
No & 32 & \\
\hline Causes of doing investigations & 175 & 3.7 \\
Friends or relatives' suggestions & 43 & 20.1 \\
Doctor's suggestions & 160 & 4.9 \\
I read about it in newspapers or the Internet & 145 & 18.4 \\
My observation for the emergence of symptoms & & 16.7 \\
Other & 297 & \\
\hline Causes of not doing thyroid investigations & 143 & 34.1 \\
Have no idea & 138 & 16.4 \\
Have no money & 108 & 15.9 \\
Fear of investigations & 96 & 12.4 \\
No need & 87 & 11.0 \\
Not available at government clinics & & 10.0 \\
Lack of time & 291 & \\
\hline Family history of thyroid troubles & 453 & 33.4 \\
Yes & 126 & 52.1 \\
No & & 14.5 \\
Don't know & & \\
\hline
\end{tabular}

\section{DISCUSSION}

Thyroid diseases are among the commonest endocrine disorders worldwide and attention to physical examination findings, combined with selected laboratory and radiologic tools, aids in the early diagnosis and treatment of thyroid endocrine disorders is fundamental ${ }^{[8]}$.

This community-based study was conducted on the general population of Riyadh city, of both sexes, to evaluate the knowledge, awareness, and practice on thyroid disorders in a representative sample. Saudi Arabia is a rapidly developing country with changes that influence lifestyle of the population towards urbanization with more progression towards general health knowledge and practice.

The results and outcomes of this study present unique information on trends in Riyadh population, their socio-demographic characteristics, and their knowledge on thyroid gland, mainly, hypothyroidism, and hyperthyroidism.
KAP of an individual can influence their behavior and management about diseases and health care. In the present study, the total number of participants was 870 among which 297 (34.1\%) were males and $573(65.9 \%)$ were females. The participants were classified into 4 age groups, most of them were in the 31-50 years old group, counting 492 (56.5\%). Only 6.6\% among the participants did not know what the thyroid gland is, while $93.4 \%$ have chosen specific answers that are facts regarding the thyroid on different levels of knowledge.Among participants, $17 \%$ related thyroid disorders to disturbances in the menstrual cycle, recurrent miscarriage, and birth of dead fetuses, while $30.3 \%$ related that to psychological factors as depression, confusion, lack of concentration, mood swings, and anxiety, $27.4 \%$ to neck and joint pain with fatigue and weight loss, and $25.3 \%$ constipation and/or diarrhea, voice changes and swelling of the neck. 
Not only general population can have poor knowledge on thyroid disorders, also physicians as in Askari et $\boldsymbol{a l l}^{[11]}$ study which was conducted on general practitioners in Iran which showed that the mean knowledge score of GPs was 39.9\% and on average, the correct responses rate to questions concerning the definition, pathophysiology, diagnosis, complications, and treatment of thyroid disorders were $39.0 \%, 39.3 \%, 48.8 \%, 34.3 \%$, and $44.6 \%$, respectively. Among our participants, $16.8 \%$ reported suffering from hypothyroidism. This prevalence is found to be less than the findings of another study conducted in Saudi Arabia by Gaffer Ali et al. ${ }^{[12]}$ in which the population was the males and females attending Ashifa Medical Complex in Albahah city showing that prevalence of thyroid dysfunction in overall males and females was $43.6 \%$, $40.8 \%$ where the cases were hypothyrodisms. It was also found that $2 \%$ among the participants suffered from hyperthyroidism. This conclusion is, however, in accordance with the findings of Gaffer Ali et al. ${ }^{[12]}$ who recorded a total prevalence of $2.8 \%$ suffering from hyperthyroidism in the studied group. Supporting these findings are the systematic review of Al Shahrani et al. ${ }^{[13]}$ which was run to determine the epidemiology of thyroid diseases in the Arab countries and showed that the prevalence of different types of thyroid disease varied between different studies ranging from 6.18 to $47.34 \%$. Prevalence of goiter was reported by several researchers in Arab world, such as Egypt, Algeria and Bahrain with $25.25,86$ and $1.7 \%$, respectively.

Regarding hypothyroidism, $30.9 \%$ answered yes to the question regarding whether or not ionized salt has a role in the treatment of hypothyroidism, when $22.2 \%$ responded with 'No' and the majority (46.9\%) responded 'I do not know'. In Rai et al,s14] study, which was carried out on women of Cosmopolitan city, Central India, only $49.20 \%$ females knew about hyperthyroidism and hypothyroidism. The majority answered 'Yes' to whether the treatment can be stopped when investigations become normal in hypothyroidism, and 'I do not know,' in hyperthyroidism. Moreover, $26.6 \%$ thought that herbal remedy can cure thyroid disorders, while Rai et al. ${ }^{[14]}$ found that $55.2 \%$ of females thought that thyroid disorders could be cured by using alternative medicine ${ }^{[14]}$. Regarding the patients that already suffer a thyroid disorder, Jørgensen et al. ${ }^{[15]}$ found that persons aware of their hypothyroidism, diabetes mellitus or hypertension reported poorer self rated health than individuals without such conditions.

Additionally, $74.6 \%$ though that cabbage, cauliflower and soy products have be avoided in case of hypothyroidism, while in the study of Sethi et al. ${ }^{[16]}$, done on hypothyroidism patient, $54.6 \%$ did not avoid eating cabbage, cauliflower, and soya. The knowledge about excessive weight gain and obesity with hypothyroidism was similar among patients in various studies. Singh et al. ${ }^{[17]}$ mentioned that $79.5 \%$ of patients attributed weight gain to hypothyroidism while $81.6 \%$ of patients in this study agreed that hypothyroidism causes weight gain. A low level of knowledge among participants was associated with lower concern, and lesser precautions taken for thyroid disorders. Thus, these participants need to receive more inputs from the health-care system and physicians.

\section{CONCLUSION AND RECOMMENDATIONS}

This study recommended that health policy makers must arrange more effective health education sessions to increase knowledge of the population and their caregivers about the various aspects of thyroid diseases and the importance of compliance with its treatment.

\section{REFERENCES}

1. Ahmad N, Panthari M, Gupta A et al. (2013): Prevalence of hypothyroidism among patients of meerut, uttarpradesh: a hospital based study. International Journal of Medical Science and Public Health, 2(3):539-542

2. Carle'A, Laurberg $P$, Pedersen I et al. (2006): Epidemiology of subtypes of hypothyroidism in Denmark. European Journal of Endocrinology, 154: 21-28.

3. Kalra S, Unnikrishnan A, Sahay R (2013): The global burden of thyroid disease. Thyroid Res Pract., 10:89-90.

4. Kalra S, Unnikrishnan A, Baruah M (2013): Thyroid: Disorders of a lesser gland. Thyroid Res Pract., 10:45-6.

5. Toft A (2003): Thyroid function tests and hypothyroidism. BMJ., 326(7384): 295-296. 
6. LandensonP, Singer $P$, Ain $K$ (2000): American thyroid association guide-lines for detection of thyroid dysfunction. Arch Intern Med., 160:1573-75.

7. Mullur R, Liu Y, Brent G (2014): Thyroid Hormone Regulation of Metabolism. Physiological Reviews, 94(2): 355-382.

8. Hanley P, Lord K, Bauer AJ (2016): Thyroid Disorders in Children and AdolescentsA Review. JAMA Pediatr.,170(10):1008-1019.

9. Khandelwal D, Tandon N (2012): Overt and subclinical hypothyroidism: Who to treat and how. Drugs ,72:17-33.

10. Chair B, Burch H, Cooper D et al. (2011): Hyperthyroidism and other causes of thyrotoxicosis: management guidelines of the American Thyroid Association and American Association of Clinical Endocrinologists. Thyroid, 21(6):593-646.

11. Askari S, Abdi H, Ahmadi S et al. (2017): Knowledge of Thyroid Disorders during Pregnancy among General Practitioners in Iran. International Journal of Endocrinology and Metabolism, 15(3): e55450.

12. Gaffer Ali AA, Altahir SA (2016): Prevalence of Thyroids Dysfunction among Saudi Adult Males and Females from (JuneSeptember 2016). J EndocrinolDiab., 3(4): 1-3.
13. Al Shahrani AS, El-Metwally A, Al-Surimi K et al. (2016): The epidemiology of thyroid diseases in the Arab world: A systematic review. Journal of Public Health and Epidemiology, 8(2), 17-26.

14. Rai S, Sirohi S, Khatri AK et al. (2016): Assessment of Knowledge and Awareness Regarding Thyroid Disorders among Women of a Cosmopolitan City of Central India. Ntl J Community Med., 7(3):219-222.

15. Jørgensen P, Langhammer A, Krokstad S et al. (2014): Is there an association between disease ignorance and self-rated health? The HUNT Study, a crosssectional survey. BMJ Open, 4:e004962.

16. Sethi B, Khandelwal D, Vyas U (2018): A cross-sectional survey to assess knowledge, attitude, and practices in patients with hypothyroidism in India. Thyroid Res Pract., 15:15-22.

17. Singh A, Sachan B, Malik NP et al. (2013): Knowledge, awareness and practices (KAP) among patients with thyroid swelling attending cytology clinic in a medical college, Meerut. Scholars J Appl Med Sci., 1:793-5. 